\title{
Assessment of Environmental Risks at Oil and Gas Production Companies Using an Integrated Method
}

\author{
Nadezhda Gorlenko, ${ }^{1, *}$, Mikhail Murzin ${ }^{1}$, and Roman Belyaevsky ${ }^{2}$ \\ ${ }^{1}$ Irkutsk National Research Technical University, 664074, 83 Lermontova St., Irkutsk, Russia \\ ${ }^{2}$ T.F. Gorbachev Kuzbass State Technical University, 650000, 28 Vesennyaya St., Kemerovo, Russia
}

\begin{abstract}
The assessment of environmental risks at oil and gas production facilities is one of the most important and relevant areas. Essentially, the results of the current assessment procedure are in most cases divorced from the real situation that is taking shape in the territory of mining operations. The main issue is the lack of a methodology that would combine an assessment of each component of the environment. The aim of this work is to justify and develop an integrated methodology for assessing environmental risks. For this, we considered the main types of environmental impacts of oil and gas production companies, and from existing methods for assessing environmental risks we selected those able to take into account the largest range of impacts. Using the resulting set of methods for assessing environmental risks, we conducted a study of the environmental condition at the oil and gas fields in the Lena-Tunguska oil and gas province, namely, the Yarakta, Iktekh, and Markovo fields. As a result, the environmental risk identified at these facilities corresponded to the "medium" level. As result, at these facilities during the risk management procedure it is necessary to implement additional measures aimed at minimizing the negative impact on the environment.
\end{abstract}

\section{Introduction}

The current global environmental situation leaves much to be desired. The constant uncontrolled use of natural goods does not allow the environment to restore the destroyed territories and to replenish the lost biological resources. Anthropogenic and technogenic loads have overpowered the ability of the environment to self-purify, which already leads to irreversible processes of degradation and pollution of existing natural environments. But at this stage of its development, humanity is not able to exist otherwise. The modern process of technological development contributes to even greater consumption of resources, the depletion of the subsoil, the divestment of animal habitats, which ultimately affects humans themselves [1]. One of such strategically important elements for the development of any country is the reserves of hydrocarbon resources, namely oil, gas and oil and gas condensates.

\footnotetext{
*Corresponding author: hope1907@istu.edu
} 
The negative impact of enterprises on the environment is controlled at the legislative level. For newly designed facilities, the legislation prescribes an assessment in accordance with Art. 32 of the Federal Law No. 7-FZ of January 10, 2002 "On Environmental Protection", and, in accordance with Art. 67, subsoil users are obliged to conduct industrial control in the field of environmental protection. And the oil and gas industry is no exception.

Earlier, when assessing the environmental impact of the operation of oil and gas production facilities, some of the natural indicators were either not taken into account at all or were concealed. Such an approach was aimed at achieving maximum economic benefits. With increasing intensity and development of the mining industry, the consequences of the negative impact have become more significant. The environment no longer has the opportunity for self-recovering, and without the developed measures aimed at reducing the negative impact, the accumulated damage over the entire period of mining operations is enormous. This incompetence and dishonesty of subsoil users caused the current deplorable environmental situation, equating mining zones with ecological disaster zones [2].

The current trend persists in almost all areas of oil and gas production. The reason is banal - the lack of interest among subsoil users themselves and, as a result, the lack of sufficient material means necessary for the restoration of resource-developed territories. At the present stage, this problem is becoming more acute for companies, but the main reason is not the consciousness of enterprises, but the tightening of requirements at the legislative level and the decline in the profitability of extracted raw materials. That is, environmental problems are becoming the most significant, but it is also more difficult to regulate them because of the significant neglect of the problem [3].

Together with a decrease in the profitability of deposits, depreciation of technological equipment and funds, leading to a deterioration in the quality of raw materials, a deterioration in the efficiency of work due to social problems only aggravates the environmental situation. These aspects have a significant impact on the productivity of companies, especially when it comes to the environmental, which lack investment [4].

Today, penalties introduced by the law are considered to be the principle that regulates unfair attitude to resource consumption, but they are, to a greater extent, not comparable with the damage to the environment and do not stir interest of subsoil users in modernizing existing production technologies - it is more profitable for companies to pay a fine than to restructure their fixed assets and production. The modern penalty system is not effective, since it has an indirect effect on the economic efficiency of oil and gas companies, and not a direct one.

An indicative example is the stimulation of the rational use of associated petroleum gas. The introduction of penalties with multiplying ratios for over-limit flaring of associated petroleum gas in conjunction with the probability of accounting for investments in the gas program for the implementation of projects for the beneficial use of associated gas as a share of these payments. Not so long ago, Russia was one of the leaders among the countries with the largest share of associated petroleum gas flaring, but only before the government decree "On the Peculiarities of Calculating Payments for Pollutant Emissions" has entered into force.

The current situation in the oil and gas industry in relation to environmental issues requires a fundamental review and implementation of a project based on the sufficient material and financial support of the relevant measures. Oil and gas production companies are forced to cut funding for environmental activities. This fact indicates a real lack of desire to contribute to a way out of the negative environmental situation [5].

To establish the sufficiency of material and financial support, an environmental damage assessment is carried out. At the legislative level, there are a huge variety of different methods and techniques for assessing the environmental impact caused by subsoil users. But all these methods are scattered, and give one-dimensional indications, which ultimately complicates 
the assessment of the state of the environment as a whole. To ensure environmental protection measures at a sufficient level, it is necessary to deviate from the assessment in the form of direct environmental damage, and switch to an environmental risk assessment with mandatory introduction at the legislative level. Environmental risk implies the probability of immediate or long-term negative changes in the environment, as a result of the negative impact, in this case man-made in nature. That is, when assessing environmental risk, not only damage is assessed, as it is done everywhere, but also the probability of its occurrence.

The basis of the environmental risk assessment procedure is the standards of the ISO 14000 series and numerous regulatory acts, one of which is GOST R 14.09-2005 "Environmental Management. Guidelines for Risk Assessment in the Field of Environmental Management." But, again, a methodology for assessing environmental risks should contain a set of indicators, based on which an appropriate level of environmental risk should be established. And depending on the final value of the risk level, the subsoil user is obliged to allocate an appropriate share of profit to compensate for the damage to the environment in sufficient quantities. The aim of this work is to develop an integrated methodology for assessing environmental risks using the example of oil and gas production facilities.

\section{Study Objects and Methods}

First of all, it is necessary to establish the elements of the environment that are adversely affected by oil and gas production facilities. Environmental pollution occurs from the initial stage, field exploration, that is, during exploratory drilling followed by well construction. During this period, pollution occurs as a result of exhaust emissions from the operation of diesel engines and drilling rigs, drilling degassers, tanks with dustlike materials, and sludge pits with drilling waste. Very often, during this period, environmental protection measures are not carried out at the drilling site due to which fertile soils and water resources are polluted with oil products and toxic components of the drilling mud. The aggravation of the negative impact occurs as a result of flushing with melt and storm water.

As a result of such an impact in the area of about 100 meters from the bore well, vegetation is completely destroyed, and at a distance of about 500 to 800 meters $70-80 \%$ of the flora realm undergoes degradation.

As a result of drilling operations, drilling waste is generated, which is accumulated in special land structures - sludge storages [6]. An important aspect in this case is the initial proper organization and preparation of the territory for a sludge storage, in order to avoid the probability of pollution with toxic groundwater waste. In addition to the petroleum products themselves, a strong pollutant is the drilling mud itself, which contains a significant amount of various chemical components [7]. The period of well construction with accumulation of drilling waste is characterized by the territorial dispersion of drilling facilities, the heterogeneity of the generated waste and temporary changes in its characteristics. During the operation of the rig, significant areas of fertile soil are divested.

In some cases, companies use outdated models of machines and equipment, technological processes aimed at obtaining maximum benefits without taking into account environmental consequences, and aggravate the already deplorable environmental situation. When performing repair work, a violation of the flushing technology for downhole equipment can lead to contamination of the site area with significant concentrations of oil products requiring disposal. This may be one of the causes of fire in the drilling area $[8,9]$.

Oil and oil products, when they enter the surface of soil and water, cover it with a film, disrupting natural gas exchange [10]. Moreover, the film subsequently deteriorates the ionexchange properties of soils, destroying populations of microorganisms up to complete degradation. On the water surface, there is a decrease in the formation of oxygen by aquatic plants, the vital activity of microcenoses of nearby water bodies is suppressed [11]. 
The atmospheric air of the regions where oil and gas production facilities operate is contaminated with hydrocarbon vapors, hydrogen sulfides and mercaptans [12]. Facilities where the technology for processing associated petroleum gas has not yet been introduced, additionally release a significant amount of combustion products in the form of oxides of nitrogen, carbon, and sulfur, and generate significant heat [13]. As a result, the most significant pollutants generated during oil and gas production are: formaldehyde, acrolein, benzapyrene, oxides of nitrogen and carbon, aromatic hydrocarbons, soot, hydrogen sulfide, sulfur dust. In most cases, companies do not use gas treatment plants to capture harmful gaseous pollutants.

To this day, industrial waste is placed in a variety of storage facilities, often without observing the required environmental standards and measures [14]. As a result, the soil and waters in the areas of operation of enterprises are subject to significant pollution. Increasing waste volumes form new technogenic landscapes. With an increase in the height of dumpings and embankments, they become more and more significant sources of dust formation [15].

The existing accounting system for determining the preventable environmental damage from environmental pollution is in a varying degree determined in a number of numerous methods. When assessing the environmental consequences, it is advisable to fully take into account all types of preventable economic damage due to environmental pollution that arises in the area where oil and gas facilities operate [16]. It was on the basis of this statement that a selection was made from all the colossal currently existing methods and techniques for assessing environmental impact, which eventually became the basis for the developed integrated methodology. The methodology of a comprehensive assessment of environmental risks makes it possible to identify problems of paramount importance for oil and gas production facilities and to determine the necessary ways and measures to reduce the negative load. For the assessment, we used the procedures for determining direct and indirect impact, resulting from the activities of enterprises, on the soil surface (in the form of exclusion zones for capital construction projects and zones of pollution with chemicals and waste), water bodies (as a result of wastewater discharge, flushing of pollutants by surface waters and water consumption of the facility), atmospheric air (organized and unorganized emissions of pollutants for the entire period of preparation and operation of the facility) and the natural component of the environment (impact on the flora and fauna of areas and aquatic biological resources).

An integrated indicator of environmental risk $\left(D_{\text {eco }}\right)$ is the sum of the results of an assessment of damage to each of the components of the environment and is determined by the formula:

$$
D_{\text {eco }}=D_{\text {atmo }}+D_{\text {litho }}+D_{\text {hydro }}+D_{\text {bio }},
$$

where $D_{\text {atmo }}$ is damage associated with the release of pollutants into the atmosphere, thousand rubles; $D_{\text {litho }}$ is damage from soil degradation, thousand rubles; $D_{\text {hydro }}$ is damage from water intake and sewage discharge into water bodies, thousand rubles; $D_{b i o}$ is damage associated with the divestment of territories from the forest fund and animal habitats, impacts on aquatic biological resources, thousand rubles.

The definition of each of the components of the integrated indicator is based on the duration of the negative impact, that is, the period from the onset of anthropogenic impact (field exploration) to the current time, or to the complete termination of the company's activities.

We chose oil and gas production companies of the Irkutsk Region as the objects of research. The Irkutsk Region has a unique geological structure, which formed significant hydrocarbon deposits that are included in the Lena-Tunguska oil and gas province - about 2.03 billion tons of oil and about 7.2 trillion $\mathrm{m}^{3}$ of natural gas. The region is considered to be a strategic source of oil and gas important for the country's foreign economic policy, as a 
source of supply for the East Siberia-Pacific Ocean oil pipeline and, in the future, the Power of Siberia gas pipeline. The integrated methodology was applied to the oil and gas production facilities of Irkutsk Oil Company LLC, which is one of the largest organizations engaged in hydrocarbon production in the Irkutsk Region. The methodology was used in assessing environmental risks at the Yarakta, Iktekh, and Markovo fields.

\section{Results and Discussion}

During the environmental risk assessment, we used information including a description of the technological processes and climatic conditions of the facilities under study, the results of environmental impact assessments, data from periodic environmental monitoring and control, the results of environmental audits and examinations, reporting documents and independent direct measurements and research in the territories of the facilities.

Due to differences in the annual volume of mining for each of the considered facilities, to compare the indicators with each other, the final value of the integrated indicator of environmental risk is expressed as a ratio to $1000 \mathrm{~m}^{3}$ of extracted raw materials.

The results of the integrated environmental risk assessment for oil and gas production facilities are shown in Table 1 and Fig. 1.

Table 1. Results of the environmental risk assessment using the integrated methodology.

\begin{tabular}{|l|c|c|c|c|c|c|}
\hline Field & $\begin{array}{c}\boldsymbol{D}_{\text {atmo, }} \\
\text { rub./ } \\
\mathbf{m}^{\mathbf{3}}\end{array}$ & $\begin{array}{c}\boldsymbol{D}_{\text {litho, }} \\
\text { rub./ } \\
\mathbf{m}^{\mathbf{3}}\end{array}$ & $\begin{array}{c}\boldsymbol{D}_{\text {hydro, }} \\
\text { rub./ } \\
\mathbf{m}^{\mathbf{3}}\end{array}$ & $\begin{array}{c}\boldsymbol{D}_{\text {bio, }} \\
\text { rub./ } \\
\mathbf{m}^{\mathbf{3}}\end{array}$ & $\begin{array}{c}\boldsymbol{D}_{\text {eco, }} \\
\text { rub./ } \\
\mathbf{m}^{\mathbf{3}}\end{array}$ & Risk level \\
\hline Yarakta field & 38.54 & 111.26 & 68.25 & 3.5 & 221.55 & Medium \\
\hline Markovo field & 34.33 & 98.98 & 60.28 & 3.6 & 197.19 & Medium \\
\hline Iktekh field & 25.96 & 85.05 & 54.35 & 3.1 & 168.46 & Medium \\
\hline
\end{tabular}

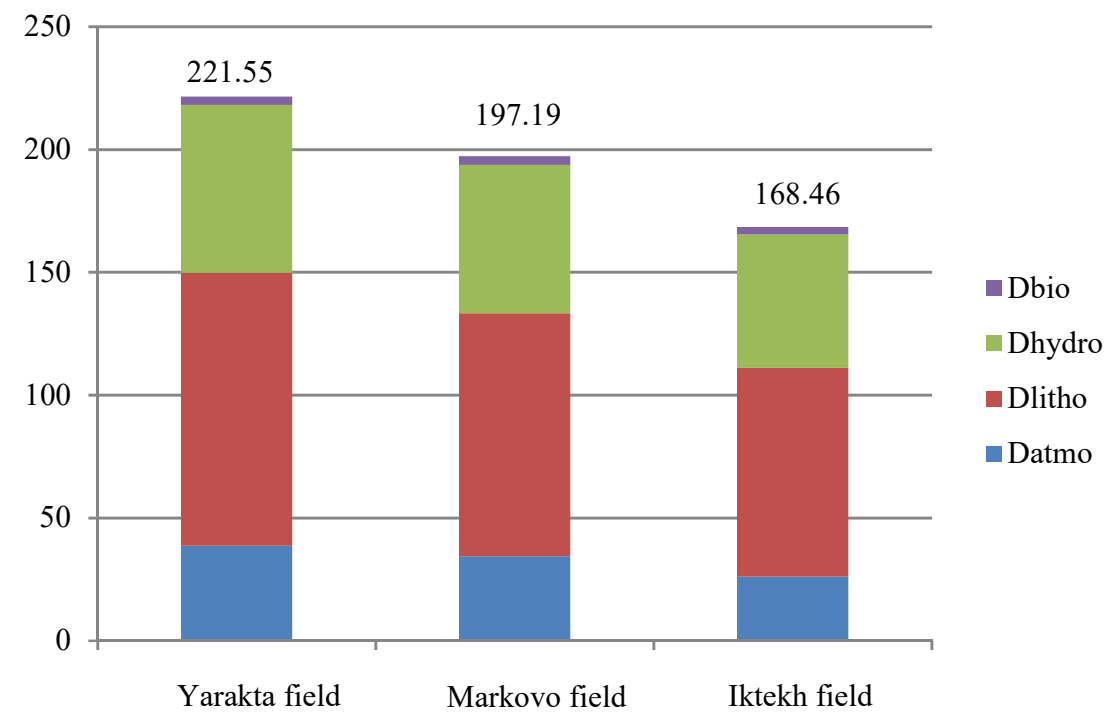

Fig. 1. Integrated indicator of the environmental risk of oil production facilities. 
According to the results of the assessment, it was found that, in general, for all the studied facilities, the risk level corresponded to the "medium" level, but the highest value of the integrated environmental risk indicator was found in the Yarakta field.

The next stage of risk assessment should be the risk management procedure, the meaning of which is to establish the best ways out of the current negative situation and monitor its development, to assess the effectiveness and correction of environmental measures. The risk management procedure itself is based on the unity of economic, social, political structures, potential costs for the implementation of technological solutions to improve the current environmental situation, various management decisions and measures.

\section{Conclusion}

The integrated methodology considered will allow comparing the environmental risks of different oil and gas production companies. Also, the application of the methodology gives a clear vision to the management staff of enterprises about the components of the environment that are most exposed to the negative impact. But the methodology, unfortunately, has a number of drawbacks, such as the need to process and compare huge amounts of data for assessment and the lack of consideration of the effects resulting from emergency situations in the form of technogenic accidents. With the further development of the methodology, these aspects will be taken into account, which will make it possible to apply a similar methodology to any of the oil and gas production companies, which will bring them one step closer to the status of "innovative" ones.

An innovative oil and gas production company needs to specialize in the full-scale implementation of the best available technologies and equipment. One of the priority areas of its activity should be a constant reduction of hazardous effects on the environment, increasing the level of industrial safety, and organizing healthy and safe working conditions for workers. The advanced nature of the projects being implemented acts as an effective alternative to the existing methods of developing oil and gas fields, which require large investments.

The introduction of the best available technologies and the modernization of fixed assets increase the level of production reliability and safety of the environment from the consequences of oil and gas production, allow for the implementation of effective and safe field development, and reduce the negative impact on the environment as a whole.

\section{References}

1. N. V. Gorlenko, M. A. Murzin, IOP Conf. Ser.: Earth Environ. Sci., 408, 012022 (2020)

2. N. Stanley, K. Tota-Maharaj, P. Eke, C. Hills, IJEEE, 1:3, 64 (2016)

3. C. Jin, Z. Zhang, IOP Conf. Ser.: Earth Environ. Sci., 189, 052004 (2018)

4. G. J. Piet, A. M. Knights, R. H. Jongbloed, J. E. Tamis, P. de Vries, L. A. Robinson, Environ. Sci. Pol., 68, 1 (2017)

5. P. Bujok, M. Klempa, V. Slivka, J. Ryba, I. Němec, V. Štastna, M. Porzer, Przeglad Geologiczny, 66:6, 379 (2018)

6. N. V. Gorlenko, S. S. Timofeeva, IOP Conf. Ser.: Earth Environ. Sci., 408, 012021 (2020)

7. I. Badrul, Int. J. Chem. Sci., 13:4, 1584 (2015)

8. N. V. Gorlenko, M. A. Murzin, IOP Conf. Ser.: Mat. Sci. Eng., 687, 066009 (2019) 
9. M. A. Murzin, N. V. Gorlenko, S. S. Timofeeva, IOP Conf. Ser.: Earth Environ. Sci. 229, 012030 (2019)

10. J. Xu, H. Wang, Y. Liu, M. Ma, T. Zhang, X. Zheng, M. Zong, Environ. Monitor. Assess., 188:2, 1 (2016)

11. S. M. Davoodi, M. Taheran, S. K. Brar, R. Galvez-Cloutier, R. Martel, Fuel, 251, 57 (2019)

12. Gorlenko N. V., Timofeeva S. S. IOP Conf. Ser.: Mat. Sci. Eng., 687, 066011 (2019)

13. E. Olaquer, Atmospheric impacts of the oil and gas industry (Elsevier, Amsterdam, 2016)

14. B. Hou, S.X. Xie, M. Chen, Y. Jin, D. Hao, R.S. Wang, Sci. Tech., 31:5, 458 (2013)

15. N. V. Gorlenko, S. S. Timofeeva, IOP Conf. Ser.: Earth Environ. Sci., 229, 012019 (2019)

16. V. Efremenko, R. Belyaevsky, E. Skrebneva. E3S Web Conf., 21, 02002 (2017) 